\title{
Doppelüberleitungsbesteck für schnellen Spülungswechsel
}

Bei der bipolaren Prostataresektion oder Greenlight-Laserung kommt es beim Austausch der Spülbeutel häufig zu Verzögerungen. Unsere Autoren haben ein System entwickelt, mit dem diese verhindert werden können.

Bei der bipolaren Prostataresektion oder Greenlight-Laserung der Prostata kommen 3-Liter-Spülbeutel oder 10-Liter-Kanister physiologischer Kochsalzlösung zur Anwendung. Wird ein einfaches, singuläres Zuleitungsbesteck besonders bei den handlicheren 3-Liter-Spülbeuteln verwendet, muss dieses bei laufender Resektion bzw. Laserung aus dem leeren Beutel in einen vollen umgesteckt werden. Dieses ist häufig mit Wartezeiten auf den Springer verbunden und kann zu einem Leerlaufen des Systems mit Eindringen von Luft in den Schlauch und - wenn nicht rechtzeitig entlüftet - die Prostataloge führen. Es entstehen sich summierende Verzögerungen.

Hier hat sich in unserer Hand die Verwendung eines „Pumpen-Doppel-Systems“ mit 2 Schlauchklemmen für die sterile Irrigation bewährt, an das 2 Beutel angeschlossen werden können (๑ Abb. 1). Während des Austauschs des leeren Beutels wird mit dem nun geöffneten zweiten Schenkel des vollen Spülbeutels ohne Störung und Zeitverzug weiteroperiert. Ist dieser Beutel leer, wird nun der inzwischen ausgetauschte Beutel „zugeschaltet“.
PD Dr. Andreas Wiedemann, Sr. Stefanie Ahlers, Witten

Korrespondenz:

PD Dr. Andreas Wiedemann

Urologische Klinik

Evangelisches Krankenhaus

im Diakoniewerk Ruhr gGmbH

Lehrstuhl für Geriatrie

der Universität Witten/Herdecke

Pferdebachstr. 27

58455 Witten

Tel. 02302/175-2521

awiedemann@diakonie-ruhr.de

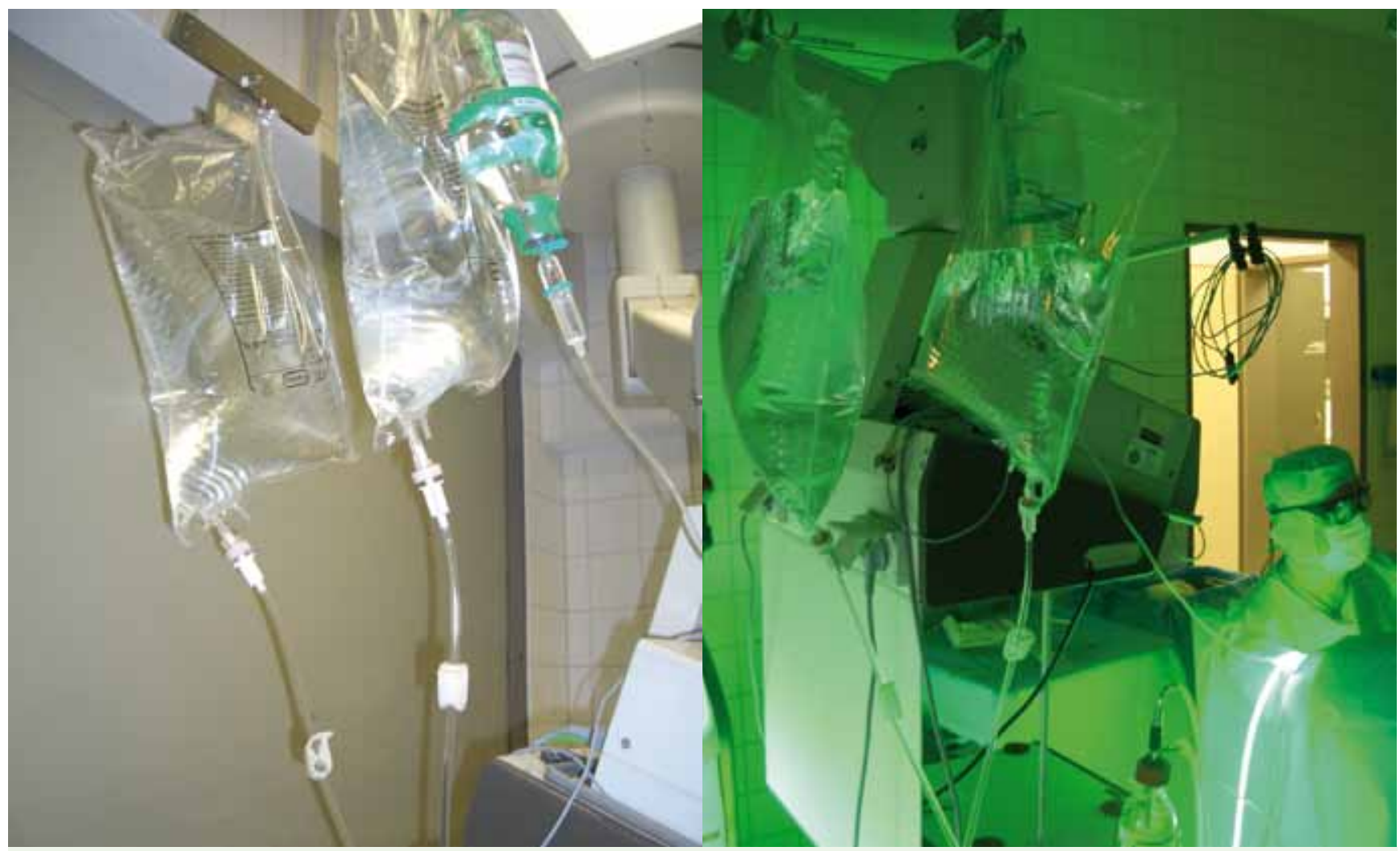

Abb. 1 Ein Doppelüberleitungsbesteck sichert eine kontinuierliche Abgabe von Spülflüssigkeit hier bei der Greenlight-Laserung der Prostata. 